\title{
Letter
}

\section{Behavior Therapy of Phobias: Predictors of Outcome}

To the Editors:

Although behavior therapy is often beneficial in treating phobias, approximately $20 \%$ of patients do not improve (Marks, 1981). Despite a few prior studies, data are limited on variables useful in predicting outcome and followup status of behavioral treatment. Therefore, we retrospectively evaluated several potentially predictive variables in 41 drug-free phobic patients ( 32 simple, 7 social, and 2 agoraphobics) who received a standard course of individually conducted exposure therapy (mean age $=33$ years, 21 males). The variables were habituation during treatment (4-point scale: rapid, slow, or no habituation, or sensitization), maintenance of treatment effect between sessions (5-point scale: improved further, maintained effect, minor relapse, major relapse, worse than before prior session), generalization of therapeutic effect to other phobic objects (5-point scale: excellent, good, fair, poor, none), followup avoidance (9-point scale: would not avoidalways avoid) and followup impairment (9point scale: no phobia-very severely disabling phobia). Mean time of followup was 7 months after completion of treatment. All ratings were done by the treating clinician.

The mean duration of therapy was 6.8 (SD 4.6) hours. Among several variables studied, the most consistent pretreatment predictors of therapy outcome were age of phobia onset (but not duration) and number of family members with phobias, as identified by the patient (proband). Mean age of onset was 19.4 (SD 13.4) years, and mean number of affected relatives was 1.4 (SD 2.5). Multiple correlations of these two variables were significant for habituation $(r=0.58, p<0.001)$, maintenance of treatment effect $(r=0.49, p<$ $0.01)$, generalization of therapeutic effect $(r=$ $0.58, p<0.001)$, and followup avoidance $(r=$ $0.54, p<0.03)$ and impairment $(r=0.61, p<$ 0.01 ). Similar patterns were observed when calculations were performed with simple phobics only (multiple $r$ 's $=0.63,0.50,0.62$, 0.61 , and 0.67 , respectively; all $p<0.05$ ), and also with patients $(n=19)$ who had agoraphobia or simple phobias associated with agoraphobia (Cameron, 1985) (multiple $r$ 's $=$ $0.55,0.41,0.67,0.64,0.65$, respectively; all $P$ $<0.05$ )

An older age of onset (even in relatively homogeneous groups of simple phobics or agoraphobics) and or a greater number of family members with phobias appears to predict both a poorer response to behavior therapy and, consequently, a poorer status at followup. These results were not specifically predicted, and therefore should be interpreted cautiously in a retrospective study. Nevertheless, the finding with age of onset is similar to that for obsessive-compulsives (Foa et al., 1983a, 1983b), and the result with family history is reminiscent of the finding of Hudson (1974) in agoraphobics. It is possible that older age of onset represents an "atypical" treatment-resistant disorder, while a greater number of family members indicates a stronger loading for the disorder (i.e., more severe) which is less treatment responsive. Note, however, that these two variables accounted for only $\leqslant 45 \%$ of the variance in treatment effect. It seems inappropriate to deny any patient a trial of hehavior therapy solely on the basis of poor prognosis as predicted by these two variables. Further research is needed. 


\section{References}

Cameron, O.G. The differential diagnosis of anxiety: Psychiatric and medical disorders. In: Curtis, G.C., Thyer, B.A., and Rainey, J.M., eds. The Psychiatric Clinics of North American: Symposium on Anxiety Disorders. Vol. 8, No. 1. W.B. Saunders Co., Philadelphia (1985).

Foa, E.B., Grayson, J.B., Steketee, G., Doppelt, H., Turner, R., and Latimer, P. Success and failure in the behavioral treatmetn of obsessive-compulsives. Journal of Consulting and Clinical Psychology, 51,289 (1983a).

Foa, E. B., Steketee, G., Grayson, J. B., and Doppelt, H. Treatment of obsessivecompulsives: When do we fail? In: Foa, E.B., and Emmelkamp, P.M.G., eds. Bchavior Therapy. Wiley, New York (1983b).
Hudson, B. The families of agoraphobics treated by behavior therapy. British Journal of Social Work, 4, 51 (1974).

Marks, I. Cure and Care of Neurosis: Theory and Practice of Behavioral Psychotherap.: Wiley, New York (1981).

Oliver G. Cameron, M.D., Ph.D.

Bruce A. Thyer, Ph.D.

Suzanne Feckner

Randolph Nesse, M.D.

George C. Curtis, M.D.

Department of Psychiatry

University of Michigan

Ann Arbor, MI 48109, USA

July 21,1986 